\title{
The Animated Film of Ne Zha in Disruptive Era: From Chinese Classical Mythology goes to Global
}

\author{
Adi Kristina Wulandari \\ \{milenia7703@gmail.com\} \\ Universitas Indonesia, Indonesia
}

\begin{abstract}
Animation has become an important part of the development of the creative cultural industry in China. An animated film based on Chinese mythology, entitled Birth of the Demon Child Ne Zha-Né Zhā zhī Mótóng Jiàngshì, or known as Ne Zha (2019), was released in the summer holidays 2019, has earned the highest box office rating throughout the history of Chinese animation and film. Ne Zha (2019) directed by Jiaozi is evidence that the Chinese animation industry has developed significantly and became interesting indicators in the context of contemporary China in the disruptive era. Therefore, this paper analyzes how Ne Zha (2019) become an effort to make brand awareness of Chinese cultural product that can to be preserved and have high selling points. The development of digital technology in a disruptive era gives a big benefit for local Chinese animator to repackage the richness of Chinese classical mythology which is displays modern elements that easily accepted both in Greater China and around the world.
\end{abstract}

Keywords: Animation Film, Ne Zha, Chinese Mythology, Disruptive Era, Brand Awareness

\section{Introduction}

Who is Ne Zha (哪吒)? For some people, the figure of Ne Zha is not as popular as the legendary Chinese animation character, Sun Wukong. Ne Zha was adapted from the Xu Zhonglin's classic novel in the Ming Dynasty era (1368-1644) entitled Fengshen Yanyi (封神 演义) or the Investiture of the Gods [1]. Supposedly, Ne Zha was born during the Shang Dynasty. Li Jing-李靖 (a military commander who subsequently holds the title "King of the Heavenly Pagoda Bearers"), and Lady Yin (殷氏) are his parents. Madame Yin gave birth to a lump of meat after going through a pregnancy for three years and six months. Li Jing almost splits the meat ball thinking it was a demon. Miraculously, Ne Zha jumped out of the cleavage in the form of a boy who could immediately talk and walk [2].

Etymologically, the name of $\mathrm{Ne}$ Zha was taken from Hindu mythology, Nalakuvara (Nalakuwara), which was later transliterated into Chinese Nàluójiūpóluó (那 羅) (婆羅). The addition of mouth radical ( $\square \mathrm{kou}$ ) to the $\mathrm{Na}$ (那) script changed the name to its current form, $\mathrm{Na}$ Zha (哪吒) or Ne Zha. According to Meir Shahar in Indian Mythology and the Chinese Imagination: Ne Zha, Nalakubara, and Krsna [3], Ne Zha was similar to Krisna's incarnation of Lord Vishnu in Hindu mythology with hidden divine power behind physical appearance as a child. The story of these two figures also presented heroism as giant dragon conquerors, where Krishna conquered Kaliya while Ne Zha conquered Ao Bing. 
In a classical mythology, Ne Zha was depicted as a boy with two hair loops on the left and right sides. As a complementary attribute, Ne Zha held a Fire-tipped Spear (火尖槍 Huǒ jiān qiāng) in his right hand while riding the Wind Fire Wheel (风火轮 Fēng huǒ lún) at his feet, carrying the Universe Ring (乾坤圈 Qiánkūn quān) in his left hand and wearing the Red Armillary Sash (浑天 绫 Hùn tiān líng). Sometimes, it was displayed in form of "Three Heads and Six Arms" (三头六臂 Sāntóuliùbì).

The character of $\mathrm{Ne}$ Zha has been adapted into various popular cultural media such as animated and live-action versions of film, television series, comics, video games, and also appears as supporting characters, along with main character of Sun Wukong the magic monkey in adaptation of Journey to the West Story. Ne Zha first appearance was in the film titled Birth of $N e$ Zha (Nézhà Chūshi-哪吒出世), produced by the Great Wall Film Company, premiered in 1928 [4]. The character of Ne Zha became popular when it appeared in classic Chinese animated film titled Ne Zha Conquers the Dragon King (Nézhà Nào Hăi-哪吒鬧海 hereinafter referred to as Ne Zha 1979) directed by Wang Shuchen and was officially released May 19, 1979 [1]. The film was later played at the Cannes film festival in 1980 and became a key moment for the introduction of Chinese mythological character, Ne Zha to the international world. In 2016, the story of Ne Zha was re-adapted into the CGI animated film titled I am Ne Zha (Wó shì Năzhā我是哪吒 hereinafter called Ne Zha 2016) directed by Shu Zhan, and most recently, an animation film titled Birth of the Demon Child Ne Zha (Nézhā zhī Mótóng Jiàngshì-哪吒之魔童降世) was released in summer holidays of 2019 (hereinafter referred to as Ne Zha 2019). Ne Zha (2019) as the first Chinese animated film production in Imax 3D format.

$\mathrm{Ne}$ Zha (2019) animation film gained success not only in China, but also in America. In China, Ne Zha (2019), directed by Jiaozi ${ }^{1}$, became the most successful animated film, far surpass of its rival, Disney's animation remake of the Lion King during its screening period in the summer holiday of 2019. Ne Zha (2019) also set a record as an animation film with the highest box office in China, surpassing the success of Zootopia (Disney) and Coco (Pixar Studio) in the past 5 years. Ne Zha (2019) was also successfully selected to represent China to be screened for the Best International Feature Film category at the $92^{\text {nd }}$ Academy Awards, 2019 [5].

The success of $\mathrm{Ne}$ Zha (2019) is an interesting indicator in the context of contemporary China in this disruptive era. In the midst of strict control mechanism imposed by the Chinese government on creative industries, film is not only required to meet general criteria as entertainment and commercial aspects, but also educational content on values adopted by China and under state control [6]. This is in line with President Xi Jinping's speech on October 15, 2014 at the Beijing Forum on Literary and Art, which is he stressed that the Chinese Dream (中 国梦-Zhongguo Meng) must affect all aspects of life in China, including the arts and culture. The Chinese Dream has become a dream held by Chinese people to be the leading nation in the world [7]. This speech, according to some observers, was a kind of guidance for the development of Chinese cultural and creative industries (CCI) discourses [8].

In the last few decades, United States and Japan have become center of world's animation industry. Although not explicitly stated, the success Ne Zha (2019) gaining box office has become evidence of significant development of growing Chinese animation industry in global

\footnotetext{
${ }^{1}$ Jiaozi's real name is Yang Yu. (Jiaozi means "dumplings" in Chinese.) He had a medical education in Sichuan, but his interest was in the field of 3D animation. For nearly 5 years, Jiaozi has written around 66 scripts, involving approximately 60 animation companies and around 1,600 animators to finalize the concept and character of Ne Zha before being appointed to the big screen animated film. Retrieved from https://variety.com/2019/film/news/china-animated-movie-Ne Zha-1203329767/.
} 
competition as competitor of the two biggest countries in animation industry. This paper shall analyze how the Ne Zha (2019) succeeded as an example of Chinese popular culture product that able to display cultural richness in form of classical Chinese myth with modern and contemporary packaging with high commercial values. The development of digital technology in the disruptive era gives great benefit for local Chinese animator to reformulate the richness of Chinese mythology and classical legend in a modern way, by utilizing sophisticated cinematographic animation technology, so it become a kind of brand awareness for currentgeneration audiences, both in the region of Greater China (Mainland-Taiwan-Hong Kong) and worldwide globally.

\section{Methodology}

Myth is closely related to the classics. The label of "classic" can be seen as recognition or reinforcement of a nation's cultural superiority. Myth is a story of gods, a religious story about the beginning of the world, about creation, fundamental events, deeds of the gods and all consequences for the world, nature and its derivative culture along with messages for those who accept the myth. The main characters in myth are usually gods, powerful person, or supernatural beings. A myth expresses and confirms values and norms of people's beliefs, it provides a pattern of behavior that must be emulated, a testimony of the efficacy of rituals with practical aims and establishing a sacred cult.

Webster's New Collegiate Dictionary defines myth as "1: A usually traditional story of ostensibly historical events that serves to unfold part of the world view of a people or explain a practice, belief, or natural phenomenon. 2: parable, allegories. 3 a: person or thing having only an imaginary or unverifiable existence, $b$ : a popular belief or tradition that has grown up around something or someone especially one embodying the ideals and institutions of a society or segment of society 4: the whole body of myth" [9].

Understanding myth is merely to understand the value elements behind the stories of the characters "Live your myth means Live Your Fantasy". Understanding a myth is also an attempt to understand the classic myth not as a fossil entity, but as a living agent [10]. So, through this paper, the author will use an intertextual approach to read the main corpus, the Ne Zha (2019) animation film, which not only inter-text with the two previous animation films in 1979 and 2016, but also with its classical mythology, the Investiture of the Gods. The relation with current disruptive era is that the success of the Ne Zha (2019) animation film lifted Chinese mythological character, the boy-God Ne Zha, as one of the best-selling films in the history of Chinese animated films and also as a crossing point in cultural and symbolic resonance through text in form of images or film, which is supported by advance technology to open possibility of reading text allegorically.

This is a literary-research based paper. With a descriptive analytical method, the author tries to understand the $\mathrm{Ne}$ Zha (2019) animation film, which was adapted from classical Chinese mythology, as a Chinese attempt to re-articulate itself repeatedly in different contexts, to different audiences and generations, within the framework projections of past prestige to the present, and also work within an ideological framework. 


\section{Findings and Discussion}

\subsection{Main storyline in the Adaptation Animation Movies about Ne Zha}

Broadly speaking, the main storyline in cultural art production that adapt mythological story of Ne Zha was about the birth, the conflict with his father, and the battle against a group of evil-dragons. Wang Shuchen [11] explained that the story of Ne Zha's adaptation since the 1950s consisted of 3 main versions: the first version was based on the main plot of mythology but cutting out superstitious and negative parts; the second version was focused on the theme of "stirring the ocean" (nào hăi 闹 海); the third version was focused on historical background. The Ne Zha (1979) classical-animation film can be said to be the most complete version because it adapts the three main storylines. The Ne Zha movies made in 2016 and in 2019 were focused on the second version of the plot, the battle between Ne Zha against the dragons.

The focus of three films of Ne Zha had their own specific implications. The Ne Zha (2019) was a "faithful" version with the main plot of its classic story, provided a fairly-long portion of the Oedipal conflict between Li Jing (Ne Zha's father) and Ne Zha, which began when Ne Zha was still in the lotus flower petals. Li Jing was worried that the lump wrapped in a lotus petal was a demonic incarnation, so he even drew his sword to destroy it. But this effort failed because of the miracle shown by the lotus petals. The father-son conflict continued. Li Jing was always troubled by $\mathrm{Ne}$ Zha's behavior and delinquency, especially Ne Zha's behavior towards the community where they lived, Chentang guan (陈塘关) village. In addition, the presence of Master Taiyi (Tài y̌̌ zhēnrén 太乙真人) and Master Shenbao (Shēn Gōngbào 申公豹) also seemed to break the patriarchal relationship between father-son. The two master figures became a kind of patriarchal institution outside of the father figure who subordinated the father figure in the interests of each teacher. The masters, who were actually brothers of the same school, tried to give influence and fight over the attitude of Devotion (XiaoConfucianism) of Ne Zha towards both of them. At the same time, the communication gap due to generation differences and similarity in character between Ne Zha and his father, made the relationship between the two more tenuous. The mediator in this conflict, the only one was Lady Yin, Ne Zha's mother.

The 2016 and 2019 made Ne Zha animation movies had main focus on the battle between $\mathrm{Ne}$ Zha and the Dragons and reducing or disguising the father-son conflict. The peak of the conflict between Ne Zha and his father, as shown in 1979 made Ne Zha movie where Ne Zha committed suicide in exchange of his life for the honor and reputation of the family due damages caused by his actions, was no longer appeared in the two latest animated films about Ne Zha. Even the ending on Nezha (2016) movie showed how Ne Zha finally lived happily again with his family and friends.

Although both movies adapted the "stirring the ocean" theme of nao hai, but the Nezha (2019) movie presented variation in the story line, especially on the opening and ending, which were different from Nezha (2016) movie version. The storyline in Nezha (2019) movie started with a narration about the emergence of the Spirit Pearl continued with the story of the birth of $\mathrm{Ne}$ Zha (more details will be explained in the Ambiguity Characterization of Ne Zha as a BoyGod with the Demons power). Meanwhile, the climax storyline was filled with the battle of $\mathrm{Ne}$ Zha against Ao Bing (敖丙), the son of the Dragon King (龙王), which ended with the union of Ne Zha and Ao Bing who both released their divine power to fight the fate and their death from a powerful lightning strike. In the end, the mortal bodies of Ne Zha and Ao Bing who were 
unable to fight the destiny against the heavenly lightning left their spirits and returned to the lotus artifacts, which were sanctified as human guardian deities.

\subsection{The Visualizations of Ne Zha as a Boy-Deity}

Nowadays, most heroic movies depict their hero or super-hero characters as an adult man or woman. The audience's imagination about the hero was constructed through a male figure (generally visualized as a good-looking, tall, a manly and mighty body posture), with a myriad of abilities or supernatural powers above the ordinary people abilities. The hero (usually) is to fall in love with a woman whose played as supporting protagonist, which representing the weak and deserve to get protection from the hero.

However, the type of characterization above does not seem to apply in animated films that carry the mythological character such as Ne Zha. Ne Zha as the main protagonist, hero or superhero in the film, is far from the mainstream depiction of this genre. In the Ne Zha (1979) movie, Ne Zha was more like the figure of androgynous children (played by men but the look was more like a woman) with a cute, funny, smart, and agile face. He also wore earrings in his ears and bracelets on his ankles. If we looked closely, the picture of the Ne Zha (1979) movie still showed elements of mixed Indian and China culture. Big, round black eyes, thick eyebrows, red lines on the forehead (in Indian culture this red line is called Sindoor which can only be used by married women), earrings and anklets, can be said to represent elements of Indian culture, while clear skin, bangs, nose and small lips seem to represent the general character of East Asian kids. If we take a look at the Ne Zha (2016) movie, Ne Zha's visualization was figured as a cute boy. He was still displayed as a basic description of the Ne Zha figure with two small buns, but this time his hair was not fringe and his face was more cutes. The influence of Indian culture could still be seen in the 2016 version of Ne Zha with the presence of a Bindi sign (a red / orange mark on the forehead right between the eyebrows as a symbol of intelligence and protection from bad influences).

Visualization of the Ne Zha character in the Ne Zha (2019) movie had significant differences compared to the previous films. The new visualization of Ne Zha was still described with a small body of a common child, big round eyes, hair with bangs and two small buns, his teeth are neat but big, and his eyes are sometimes shown like sleepy eyes. What was unique and different from the previous character of Ne Zha, in the Ne Zha (2019) movie, Ne Zha's aura was a bit far from the cute impression of children, his face showed intelligence, as well as delinquency, stubborn character, temperamental, rebel, but still agile and easy going as typical of "anak zaman now" (nowadays children) character.

Comparison of Ne Zha's visualizations in the three films can be seen from the following images as follow:

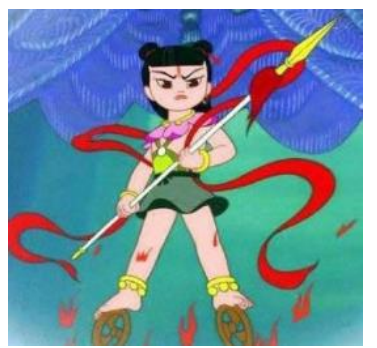

Fig. 1. Ne Zha (1979) [12].

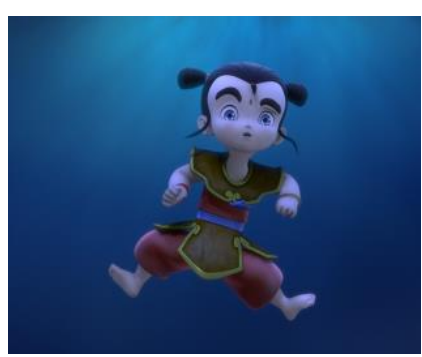

Fig. 2. Ne Zha (2016) [13].

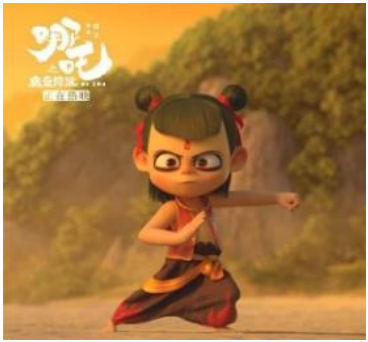

Fig. 3. Ne Zha (2019) [14]. 


\subsection{The Characterization of Ne Zha is Different from Common Character of Boys}

The varied visualization of the physical appearance of Ne Zha as shown above, showed a shift in the visualization of Ne Zha's character at different periods. The visualization of Ne Zha in the 1979 and 2016 animated versions emphasized cute and funny faces typical of young boy. It went along with the voice dubbing of him with a light timbre typical of little boy. In the $\mathrm{Ne}$ Zha (2019) movie, the visualization and voice dubbing of his character underwent a change. Image 3 showed that his character was no longer cute and funny. Two big, round and wide-eyed eyes tend to show his temperamental and rebellious character. Voice dubbing also supported the change of his character in the Ne Zha (2019). Timbre's voice sounded heavier, rather hoarse to reinforce the image of Ne Zha's character as a rebellious and temperamental young-boy. The change in the visualization of Ne Zha's character in the Ne Zha (2019) showed his character that was no longer a 3-year-old toddler, but rather a picture of a grown-up boy in adolescence, or it can be said that the character of Ne Zha experienced "maturity" as seen from physical visualization and his voice.

However, the innocent behavior of the typical toddler Ne Zha in the Ne Zha (2019) movie was still shown at least in some scenes that showed how he was so happy playing shuttle cock (time scene 20.33; time scene 53.11). The naughty and mischievous behavior of a young boy was also shown by Ne Zha in several scenes, including when he succeeded in deceiving a group of children who always hate and did not want to play with him (time scene 26.00). Furthermore, in the scene when Ne Zha succeeded in deceiving Master Taiyi who forced him to be his disciple to learn sorcery (time scene 32.03). Unexpectedly, Ne Zha decieve Master Taiyi, he had actually succeeded in learning magic spells without the knowing of him.

The characterization of Ne Zha as an innocent, naughty, ignorant, but smart young-boy remained a common thread that always appeared in all three films, but with a portion that felt different. In the 1979 and 2016 films, Ne Zha's childishness was very dominant, but in the Ne Zha (2019) movie, the portion of his childish characterization was reduced and changed to a transitional character toward unruly teenagers and rebels.

As a young leader, Ne Zha in the Ne Zha (2019) movie has been able to express opinions and protests frankly, especially when he felt discomfort. This could be seen in the scene when Lady Yin persuaded and promised him to play together again on another occasion. At that time, Lady Yin could not continue playing with him because suddenly she received a report from her men to immediately go to eradicate fish evil spirit that had injured dozens of people (time scene 21.36). Even though he tried to understand his mother, he was disappointed and angry that he could not hide it. Ne Zha who was not even 3 years old was even able to frankly say to her mother, that, “everytime you always say same words, I am tired to hear that (每次都是同样的话,

我早习惯了.....”. Ne Zha looked disappointed and sad when look at his mother still leaving him to carry out the task (time scene 21.53-22.31).

In time scene 40.21, Ne Zha able to express his opinion and feeling when he was listening to an explanation from his parents and Master Taiyi about his origins. At that time, Ne Zha had protested to them because he felt he was being locked up. Ne Zha stated that he was aware, his behavior troubled many people, especially villagers, but he argued that he was doing it as an outlet for his frustration because there were no children who wanted to be friends and play with him. Ne Zha felt that his physical appearance, his kungfu skills and intelligence were different from common young-boy. So, it can be said, Ne Zha does not connect with her peers. This caused Ne Zha to feel bored. Everyday Ne Zha only had his mother, who wanted to play with him. His mother then explained that this was not his fault. Ne Zha was indeed different because they had ordinary human of parents, while he was born from the the Pearl of Spirit that has the 
power of a god equivalent to protect human from the demon's power. The explanation made $\mathrm{Ne}$ Zha then tried to dedicate his life, help his parents to conquer the evil creatures that disturbed the life of the villagers.

\subsection{Ambiguities of the Character of Ne Zha as a Boy-Deity with the Demon Power}

As explained in the Introduction section, in classical Chinese mythology, the character of Ne Zha was told as one of the gods with child physical condition who served as a human protector. In the Daoist school, Ne Zha was also called the Central Marshal (中坦元帅 zhōng tăn yuánshuài). After becoming a protective deity, he was given the title of the Third Lotus Prince (莲花三太子 Liánhuā sān tàiž̀). The lotus became an artifact that was attached to the figure of $\mathrm{Ne}$ Zha because he was born from a lump of meat wrapped in a lotus artifact. This was clearly shown in the early part of the Ne Zha (1979) movie. After the lotus petals opened layer by layer, then he came sitting curled up naked. Baby Ne Zha then pulled out a lotus leaf which miraculously became a cloth and a red ribbon that tied two buns on his head. With this appearance, he jumped out of the lotus artifact and began his life story.

In the Ne Zha (2019) movie, lotus artifact became the shell of Chaos Pearl (Hùn yuán zhü 混元珠) so they did not continuously absorb life energy. With Yuanshi Tianzun (元始天尊) one of the highest gods in the Daoist school, he divided the Chaos Pearl into two parts, each representing the life force of the Spirit Pearl (灵珠 Líng zhū) and the devil force which was a magic pill called the Demon Orb (魔丸 mó wán). He also ordered one of his students, Taiyi, to guard the lotus shells from the attack of evil forces who intended to steal the Spirit Pearl. Tianzun placed the curse of the Demon Orb, which in three years would be crushed by lightning strike. Tianzun then ordered Taiyi to take the Spirit Pearl to be reincarnated as the third son of Li Jing, who was later named Ne Zha.

Shen Gongbao or Shen (Taiyi's younger sibling) conspired to steal the Spirit Pearl and in the ensuing battle, the Devil Orb was placed on the ritual altar instead, which caused Li Jing's pregnant wife, Lady Yin to give birth to a child, Ne Zha, whose demonic character is clearly visible. While the Spirit Pearl that was successfully stolen by Shen was later reincarnated as the son of the Dragon King (龙王) named Ao Bing (敖丙). In the middle up to the last half of the $\mathrm{Ne}$ Zha (2019) movie, he was told to use his demonic power to follow his parents conquering the evil creatures that disturbed human life. However, due to super-natural birth which carried the power of the Demon Orb, evil and inclined tendencies dominated his character.

The super-natural of Ne Zha's birth from the lotus artifact strengthens the figure of him as a super-human figure, which was a distinctive marker in the story of classical mythology. The super-natural birth of his character became an opening description of the complexity and ambiguity of the nature and the struggle that he did. Ne Zha was a boy who was not easy to be controlled, because he was dominated by evil force of the Demon Orb and also because of his super-natural birth process that made the strength in him difficult to be controlled in the usual way.

Thus, it could be said that the Ne Zha character was an evil force that was wrapped in a tiny and naive body of a young-boy who strived to conquer the evil for the creation of world harmony. It was this complexity and ambiguity that made his character interesting, because the dichotomy of evil forces and goodness was unclear. How do we see this Ne Zha character? Does it represent evil, or does it remain a form of God power? Here is the uniqueness of the classical Chinese mythology and also perhaps the other world mythological stories that always brought the heroic figures in 'gray' status which stand in two worlds, between evil and good. 


\subsection{The Complexity of Relationship between Ne Zha and Other Characters}

The relationship between Ne Zha and other characters in the three films showed the complexity of each character in the movie. Based on the Ne Zha (1979) movie, the conflict between father-son, Li Jing and Ne Zha, was characterized by complexity because of the presence of master figures. As discussed in the previous parts about Ne Zha, the figure of the Master Taiyi and Master Shen created a new patriarchal structure for Ne Zha. Due to a greater focus on the role of Master Taiyi and his wise nature, he seemed to replace the role of the father and became a role model for Ne Zha. The master's figure looked like trying to replace Li Jing's role as 'father'. The figure of a father who was supposed to be a protector for his son was not shown by Li Jing to Ne Zha. The presence of a master between the father-son creates a triadic pattern [15], an equilateral triangle where the three sides not only influenced each other, but also created domination and also as aligners, when finally created a balance between the three sides. This kind of relations between Li Jing - Master Taiyi - Ne Zha, might be read as a reason why Ne Zha became a naughty boy and could not be easily subjected to his father. The balance was then reached by the decision of Ne Zha who was willing to commit suicide to pay the debt of his unwanted birth and brought disaster to the honor of the family. The decision created a temporary harmony because then the Master Taiyi "resurrected" Ne Zha into a hero who finally fought against the 4 main figures of the Dragon.

The triadic pattern of the complex relation of father-master-boy was no longer displayed in the next two Ne Zha movies in 2016 and 2019. The figure of father and master actually became part that strengthened the heroic character of Ne Zha who was shown when fighting the Dragon. The father-son conflict ended with Ne Zha's departure from home to wander and fight against evil creatures, the water demon and the dragon king. In his wanderings, Ne Zha met with Master Taiyi who later gave him the weapon of the Universe Ring, the Wheel of Fire and the Red Shas. In the end, Ne Zha returned to his father's arms, in his original form of a toddler and living happily with his family and the villagers of Chentang guan.

Ne Zha's relationship with other figures also the same in the Ne Zha (2019) movie. Triadic patterns of father-master-boy conflict no longer emerged. Father and Master Taiyi showed supports for Ne Zha to be a good boy, despite having a more dominant evil nature. Li Jing as a father even prayed to Yuanshi Tianzun to revoke the cursed fate of Ne Zha. In this film, Li Jing's sacrifice was shown that he was willing to exchange his life through 2 pieces of Joss Papers, so that his life was revoked as a substitute for the life of Ne Zha who was condemned to die at the age of 3 years old. The Master Taiyi figure tried hard to make Ne Zha as his disciple. However, the ability and intelligence of Ne Zha, which was above the ability of common young-boy, reduced his eager to learn from Master Taiyi. However, the wise temperament and quality of Master Taiyi was then visualized with a fat body and humorous figure in this film and in the end, it was never officially displayed that he made Ne Zha as his disciple. However, Master Taiyi always helped Ne Zha when he was having a hard time and never felt angry even though $\mathrm{Ne}$ Zha repeatedly avoided him.

The complicated relationship in the Ne Zha (2019) movie, actually appeared between $\mathrm{Ne}$ Zha and Ao Bing. Both of them are the characters with confused destiny. Ne Zha, who was supposed to be born from the Spirit Pearl in order to have good qualities, was actually born from the Demon Orb because of what Master Shenbao did. The Incarnation of the Spirit Pearl actually happened to the dragon egg which became the forerunner to the birth of Ao Bing. Ne Zha and Ao Bing became two children who grew up in families with different characteristics from them 
due to this confused destiny. Ne Zha grew up as a boy dominated by evil traits, while Ao Bing grew into a dragon spirit that actually has a gentle nature and a gorgeous face.

The complexity of the relationship between Ne Zha and Ao Bing was increasing after their meeting on a beach after the two of them helped each other defeat the evil spirit of the water. At that moment, Ne Zha admitted that Ao Bing was the only friend he had, who wanted to play shuttle cock with him, besides his mother. Ao Bing also promised to always be a good friend to Ne Zha and willing to appear on the land whenever Ne Zha called him.

The complex friendship between the two characters with the confused destiny reached the climax when Ne Zha and Ao Bing had to fight each other on behalf of their respective groups, at the celebration of Ne Zha's third birthday. Ao Bing was forced to defend the Dragon group who wanted to destroy the human, especially Master Taiyi who reported the confused of Ao Bing's fate with Ne Zha to the gods in the kingdom of heaven. Quietly, Ao Bing formed a frozen cloud of water that if it melts, the water will drown Chentang guan village and its entire population, including the Ne Zha family. Ne Zha, who was initially very angry because both parents and Master Taiyi kept their birth origins and curse upon him, finally melted after knowing that the father had prayed to replace himself to face the curse of destiny.

Based on all mighty power he possessed, Ne Zha fought against Ao Bing. The evil power of the Dragon group was successfully conquered by Nezha. A very epic battle between Ne Zha against Ao Bing became the initial climax of the Ne Zha (2019) movie. Climax continued with Ne Zha's union with Ao Bing to face the fate of his death by lightning strike (time scene 01.37.43-01.47.27). Ao Bing held Ne Zha's hand in a bolt of lightning then released their respective strengths, which could be seen from the signs of Yin and Yang separated on their foreheads. The Yin and Yang signs eventually reunite into the Chaos Pearl ball. The power of the heavenly lightning who was about to suck the Chaos Pearl still hadn't died down. Master Taiyi then threw a lotus artifact to wrap the Chaos Pearl and defused the power of lightning.

Finally, the Chaos Pearl was stored again in a lotus artifact. The pearl was a form of union of two figures, Ne Zha who represented the forces of evil and Ao Bing who represented the forces of good. The ending part might be seen as reinforcing the complexity and ambiguity about the dichotomy between 'god' and 'evil', which may be clearly structured in other stories that the forces of evil will definitely be defeated by the forces of God. It was at this point those Chinese heroic films showed their unique characteristics. One typical Chinese element values Daoist, appeared to convey moral messages through cultural products in form of animated films. In Daoist philosophy, everything must have a Yin side and a Yang side, which shall create balance and harmony.

\subsection{The Adaptation Movie of Ne Zha Myth as a Text in the Disruptive Era}

The myth about Ne Zha might be said to have significant changes in the Ne Zha (2019) movie. Since the 1979 version, the visualization of Ne Zha with classical animation technology has been able to encourage international film industry at that time, that China has opened itself to the outside world. Through the animated film which was still subordinate in China film industry, it was able to display its other mythological figures besides Sun Wukong, who had already been known globally. The first Ne Zha's film (1979), screened at the 1980s Cannes Film Festival, could be interpreted as an allegory of China in the era of reform and opening up-policy which led by Deng Xiaoping. The first Ne Zha film (1979) was a production that ended 10 years of the Cultural Revolution and signified the continuation and simultaneous shift in the representation of a revolutionary hero. 
The second Ne Zha film (2016), with a better animation technology compare to the 1979 version, was able to re-figure the myth of Ne Zha. The storyline of the Ne Zha (2016) movie succeeded in disguising the father-son conflict as seen in the $N e$ Zha (1979) movie and demonstrating the Consecrated value of Confucian teachings between children to both parents and teachers. Modern packaging in the visualization of the character of Ne Zha and a happy ending was very child-friendly. The complexity of the relationship between characters was not very visible in this film, but the ability of this film to disguise the father-son conflict could be said to be a kind of 'foundation' for the next Ne Zha (2019) movie, although it was never explicitly stated so. However, at least in terms of chronological release of the two films, the $\mathrm{Ne}$ Zha (2016) movie can be said to be an updated adaptation of Ne Zha myth in animated film.

However, the Ne Zha (2016) movie, in terms of box office achievement, was indeed below its successor, the Ne Zha (2019) movie. This might be due to the storyline factor which tend to be less complicated, visualization of cartoon characters, 'children' preference and less dynamic cinematic. The colorful nuances throughout this film tend to be soft or less sharp, because they did not adopt in HD or 3D technology. Visualizations of other figures such as Master Taiyi, Ne Zha's friends, and water evil spirit, appeared to lack the typical Chinese characteristic.

Stepping into the Ne Zha (2019) movie, this film was a revolutionary Chinese animation, especially in this disruptive era. This film was not only revolutionary in cinematic technology animation, but also on storyline and characterization. The change in the visualization of Ne Zha from sweet, handsome, funny young-boy to a kid who was not handsome, funny, fierce and temperament, against the mainstream visualization of children's characters in modern America and Japan animation typical. This film, which was actually intended for all ages, bravely to 'state' that the hero did not have to be sweet or good-looking, because at least it was able to represent the audience in the real world, that a hero did not all have an ideal. Ne Zha was not a figure that looked fine, but instead he was a dynamic character, good and evil went hand in hand, although the evil nature was dominant in the character of last Ne Zha film.

The dynamic-character, showed the complexity of real human nature. In fact, there was no human who was truly good or truly evil, not even superheroes. Life in this world was also the way it was, nothing was static, the 'evil' could also be 'good', and vice versa. The complexity and ambiguity of Ne Zha and Ao Bing in this film climaxed in the scene of the union of Ne Zha and Ao Bing, followed by the unification of the Yin and Yang marks from the foreheads of the two characters, as in the following picture:
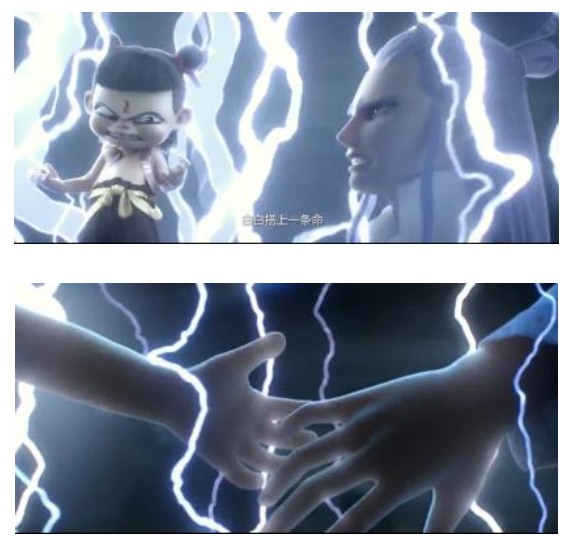
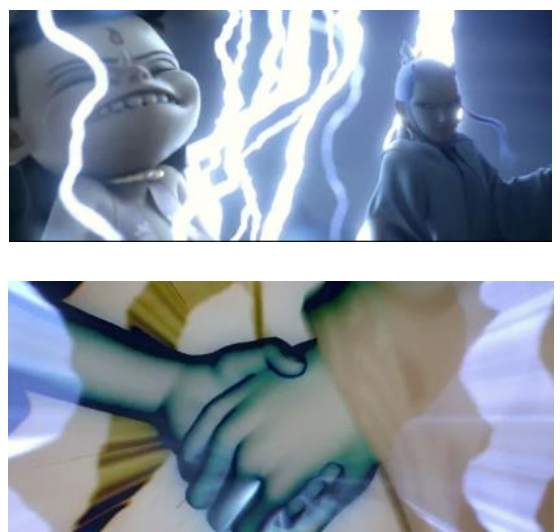


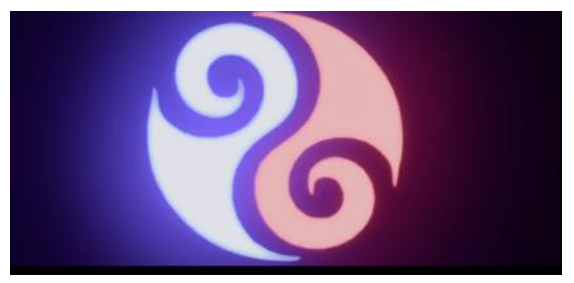

Fig. 4. 01.39.14-01.39.55

Highly sophisticated cinematographic technology could increase the visibility of the imagination about the union of two forces, good and evil, into a symbol of harmony and complementary lives. Imagination of the awesomeness and grandeur on the merge of these two forces became apparent with the sharp and live color technology as shown in the image above. It also created 'psychological' and 'thrilling' effects in delivering the message that life in this world truly was complementary.

Through sophisticated cinematographic technology, Ne Zha's animated film in this disruptive era did not only interact with two previous films with the same character and its classic mythological story, but also inter-texted with fundamental values in the reality of life. The values displayed were not only typical Chinese values, namely Confucianism-DaoismBuddhism, but also on the unification of the Yin and Yang symbols in image 3, including universal values such as friendship. Friendship was not only meant as a union of relations between the same entity, as between fellow good entities, but also friendship that connected two complementary entities, namely between 'good' and 'bad'.

\section{Conclusion}

In the last few decades, as generally known, United States and Japan have become the center of the world's animation industry. The $\mathrm{Ne} Z \mathrm{Zha}$ (2019) animated film, as one of cultural products of local Chinese animators, became evidence that the animation film industry in China is experiencing significant development. The advanced animation technology used in this film was proven capable to develop a visual imagination of Ne Zha's power as one of the gods in the physical form of a tiny child's body. Sophisticated animation technology made Ne Zha a reflective figure which deconstructed general picture of a hero in a film. A person with small body, a face that was not handsome, a hard temper and temperamental, did not mean you cannot be a hero. The hero figure through Ne Zha was a person who was able to change the evil forces that reside in his body into a force that brings balance to life. Evil was a process to go for good. In line with a statement that 'understanding a myth is not merely understood the value elements behind the stories of the characters but also to develop imagination and fantasy based on the richness of art and culture of a nation', the Ne Zha (2019) movie actually stated, "Live your myth means Live Your Fantasy". Understanding Ne Zha as a classic myth was also an effort to create brand awareness of Chinese cultural products that could be preserved and have a market value, not only as a 'fossil' entity or a relic of the past, but also made it as a living agent and (can be) visualized all the time. One strategy to keep myth alive was through animated films. The development of digital technology in the disruptive era gave great benefits to local Chinese animators to refigure the wealth of classical Chinese mythology in such a way that it was able 
to display modern elements that were easily accepted by current generation, both in the Greater China region and throughout the world.

\section{References}

[1] S. MacDonald, Ne Zha naohai (Ne Zha Conquers the Dragon King) Scar animation and an ending. London \& New York: Routledge, 2016.

[2] J. Roberts, Chinese Mythology A to Z. New York: Chelsea House Publishers, 2010.

[3] J. Kieschnick and M. Shahar, India in the Chinese imagination: Myth, religion, and thought. University of Pennsylvania Press, 2014.

[4] Jiaozi, "Ne Zha," 2019. [Online]. Available: https://movie.douban.com/subject/26413854.

[5] P. Brzeski, "Oscars: China Selects 'Ne Zha' for International Feature Film Category," The Hollywood Reporter, 2020. [Online]. Available: https://www.hollywoodreporter.com/news/2020-oscars-china-selects-ne-zha-internationalfeature-film-category-1246055.

[6] W. Zhang, "Chapter 13: Contemporary Chinese Entertainment Films: A Summary of a Symposium Translated by Fu Binbin," in Contemporary China: Critical Debates 1979-1989, Westport: Greenwood Publishing Group Inc., 1993, p. 138.

[7] J. Hsiung, The Xi Jinping era: his comprehensive strategy toward the China Dream. CN Times Books, 2015.

[8] H. Ma, "Chinese cultural and creative industries and the struggle for rights in Chinese Opera," Law, Soc. Justice Glob. Dev., vol. 22, pp. 61-72, 2018.

[9] W. K. Ferrell, Literature and film as modern mythology. Praeger Publishers, 2000.

[10] H. Morales, Classical mythology: a very short introduction. OUP Oxford, 2007.

[11] S. Macdonald, "Animation as Intertextual Cinema: Nezha Naohai (Nezha Conquers the Dragon King)," Animation, vol. 10, no. 3, pp. 205-221, 2015.

[12] 源大 觉 , “Folk Religion," Pinterest, 1979. [Online]. Available: https://www.pinterest.com/pin/844354630116503327.

[13] Animex, "Ne Zha," Animex, 2016. [Online]. Available: http://en.animex.com.cn/.

[14] P. Zhang, "Chinese animated legend Nezha makes box office history, roaring past The Lion King," South China Morning Post, 2019. [Online]. Available: https://www.scmp.com/news/china/society/article/3021368/chinese-animated-legend-nezhamakes-box-office-history-modern.

[15] A. E. Larasati, "Mengenal Peranan Pentingnya Warna dalam Desain Grafis," International Design School, 2018. [Online]. Available: https://idseducation.com/mengenal-berbagai-macamcolor-harmony/. 